\title{
THE RAPID PROTOTYPING AS A SOLUTION TOOL: QUANTITATIVE RESEARCH ON SCIENTIFIC PRODUCTIONS
}

\author{
Sérgio Levi Souza de Oliveira', Allyneanhy Gade Nunes Alves Oliveira² \\ 'Universidade Salvador (UNIFACS), Brasil, sg.levi10@gmail.com \\ ²Universidade Federal da Bahia (UFBA), Brasil.
}

\begin{abstract}
With the pandemic scenario, the demand for Personal Protective Equipment (PPE) grew rapidly. There was a necessity for a rapid manufacturing of these, for the safety of health professionals and the global population, in addition to curbing contamination. In response to the scarcity of supplies, one of the solutions found for the implementation of 3D printing with this purpose. The article presents a quantitative research containing a sample of 41 scientific publications, from March to July 2020. The objective is demonstrate the relevance of rapid prototyping as a catalyst tool for the production of products in the short time. From the data, we conclude that, the pandemic stimulated the application of $3 \mathrm{D}$ printing in medicine, with the potential to expand to other areas.
\end{abstract}

Keywords: 3D Printing; Covid-19; Rapid Prototyping; Quantitative Research.

\section{PROTOTIPAGEM RÁPIDA COMO FERRAMENTA DE SOLUÇÃO: PESQUISA QUANTITATIVA DE PRODUÇÕES CIENTÍFICAS}

Resumo: Com o cenário da pandemia, a demanda por Equipamentos de Proteção Individual (EPI) cresceu aceleradamente. Surgiu a necessidade da rápida fabricação destes visando a segurança dos profissionais de saúde e da população global, além de frear a contaminação. Em resposta à escassez de suprimentos, uma das soluções encontradas foi a implementação da impressão 3D com esse propósito. $O$ artigo apresenta uma pesquisa quantitativa contendo amostra de 41 publicações científicas, no período de março a julho de 2020. O objetivo é demonstrar a relevância da prototipagem rápida como ferramenta catalizadora para produção de produtos em curto prazo. A partir dos dados, conclui-se a veracidade de que, a pandemia estimulou a aplicação da impressão 3D na medicina, com potencial de ampliação a outras áreas.

Palavras-chave: Impressão 3D; Covid-19; Prototipagem rápida; Pesquisa quantitativa. 


\section{INTRODUCTION}

In 2020, the world was surprised by the conjuncture of the coronavirus pandemic, which caused changes in your entirety in people's habits and routines. Due to the form of contact of the disease in which it spreads through droplets of the nose or mouth and the proximity to the infected, measures were taken so that the world population could avoid becoming contaminated. Some of these measures was to adopt isolation, the constant use of alcohol in gel and masks while being close to other people.

In this scenario, due to the increase in the number of cases of covid-19, it was necessary to gather scientific knowledge in an accelerated way, so that improvement of equipment such as mechanical ventilators and faceshields became fundamental for the protection and care of professionals and patients. The engineering and design, in their multidisciplinary perspectives of transformation and innovation, have entered into the support of the development of faceshields, in addition to other impactful solutions to assist everyone in protect themselves from the dangers of the disease. One of them was the production of PPE, which compared to conventional means of production, three-dimensional (3D) printing technologies are offering multiple benefits, flexibilities and customizations [1].

For the development of faceshield's projects, designers and engineers from various parts of the world had to work with limited materials and adapting to this new demand. Access to masks, especially in healthcare units, was becoming remote, so design and engineering as solver needed to achieve rapid development of new products for emergency and global demand, using the 3D printer as an aid. Rapid prototyping to generate plastic components of the product was a crucial support tool. According to Baião [2], 3D-printing does the same service as the conventional printer, only instead of simply placing the ink on top of a sheet, it creates objects in 3 dimensions. Therefore, 3D modeling and printing collaborates with the creation of objects that sometimes seem unreachable, becoming an ideal alternative for the context of pandemic.

In this way, the article examines quantitatively works with propose the use of rapid prototyping and 3D-printing applied to innovations and protection products against covid-19, in the period from March to July 2020. The relevance of the theme, in addition being a recent research and not much studied, indicates a potential of the intensified use of rapid manufacturing tools in medicine and chances for application in other areas in the post-covid world. The structuring of the article is divided into research methodology, the results and discussions and, finally, the conclusions of the work.

\section{METHODOLOGY}

For the questions in the article to be constructed, a bibliographic research was carried out at the beginning of the study to understand the existing research related to the subject in question. 
Subsequently, the present research used the quantitative approach. Quantitative research is very different from qualitative research, in the results obtained through research are quantifiable [3]. It focuses on objectivity. Influenced by positivism, it considers that reality can only be understood based on the analysis of raw data, collected with the help of standardized and neutral instruments [3]. Therefore, the study presented is based on a sample of works published on the theme, between the period from March to July 2020. The data collected from the publications were transformed into numbers and subsequently analyzed.

For collect the productions, we searched the databases Science Direct (Elsevier), CAPES Periodical, Scielo, Medline, and Research Gate. The choice of these databases is due to their scope and influence in the academic and scientific world, in addition to having a wide range of publications available. In order to standardize the research, five keywords were used that refer directly to the chosen theme, namely: "3D", "Covid-19", "Design", "Print" and "Prototype". For the last two, variations such as "printing", "printed" and "prototyping" were accepted, since the word radical is the same and its variations suit the researched context. Another consideration was the mandatory appearance of the term "Covid-19".

In order to simplify the research and achieve results quickly, the five keywords were inserted in the order presented above, without the use of separators, for search engines in the databases. In many cases, the use of the five words together did not generate results, therefore, only the three main terms "3D", "Covid-19" and "Print" were used for these cases. Were considered the publications whose terms were found in either the title of the publications or in the keywords, so that those containing at least three of the selected terms were contemplated. The computed publications had their specific information stored in an Excel spreadsheet, for later analysis of the data whose result generated inferences about the analyzed theme.

\section{RESULTS AND DISCUSSION}

In the five databases evaluated, a total sample of 41 publications was identified within the established criteria. The publications computed in the Excel spreadsheet had their data grouped into 11 columns. The columns stored, in this order, the following information: item number, publication date, authors number, type of publication, country, databases and keywords (with one column for each of the chosen keywords).

\subsection{Sample results}

With the data sample defined, we sought to segment them into five analyzes, so that a graph was generated for each analysis in order to facilitate the visualization and interpretation of the constructed database.

When it stratifies publications based on the country where it was published, there is a latent participation from the United States. Then, we can understand the commitment of European countries, whose representation is greater with nine countries. In addition, in terms of continents, the number of publications between the 
American and the European is equivalent, totaling 17 publications in each one. According to current data from the World Health Organization (WHO) dashboard, an exponential increase on number confirmed cases of covid-19 is noticeable on both continents [4], which may be related with demand for quick solutions to contain the virus. The data of the distribution by countries can be checked in figure 1 .

Figure 1. Distribution of publications by countries. (Source: Authors)

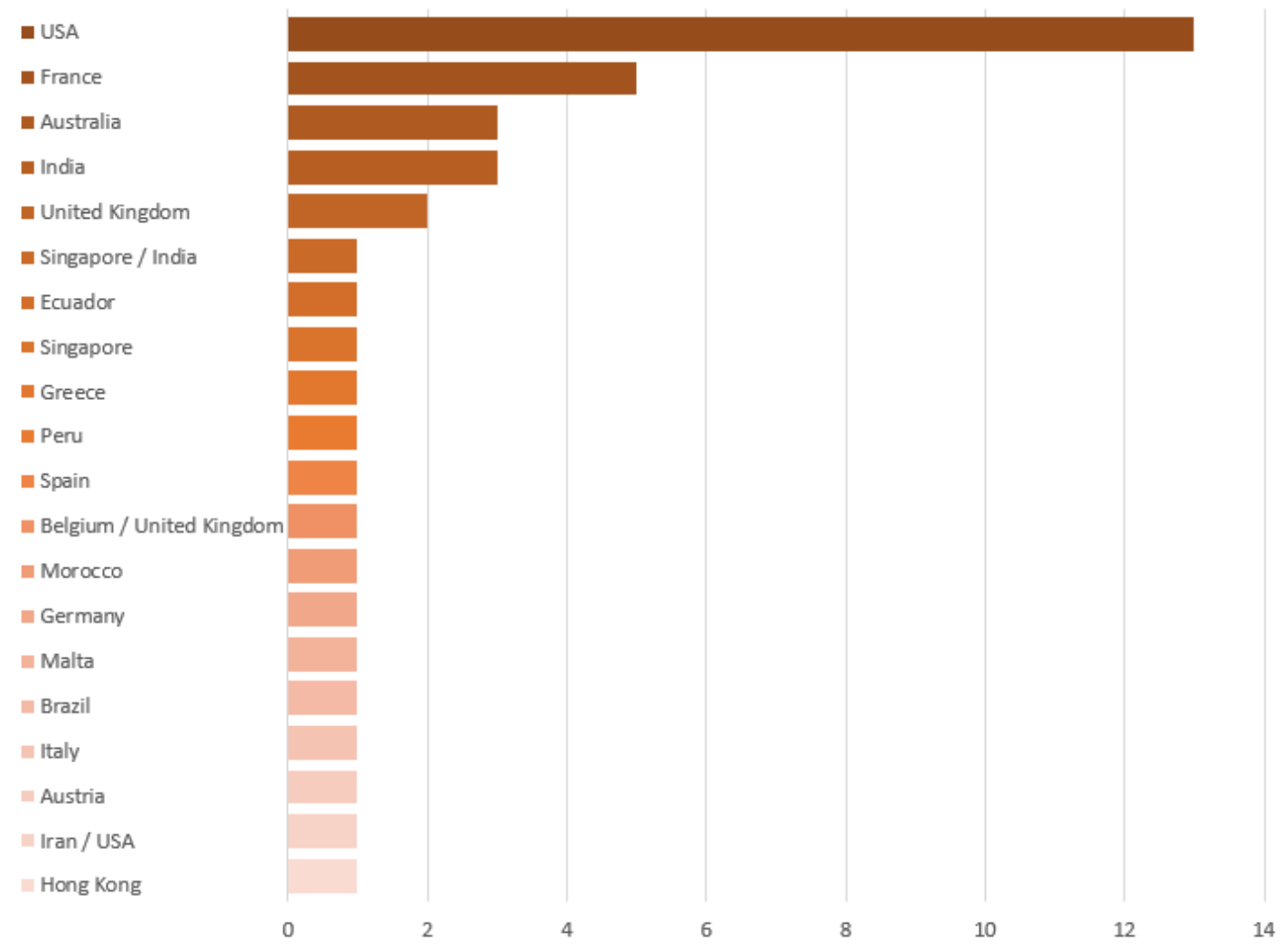

Analyzing the same sample with a focus on keywords, a high frequency of the terms 3D, Covid-19 and Print, was seen like in figure 2. It was expected that research on the pandemic theme was become more common due to the moment in history and the challenges imposed by it. It is noticed that use of techniques involving 3D printing has been widely studied, especially applied to medicine. Rapid manufacturing was a technique used, especially for making products that would provide protection against the virus to health professionals and the population.

Figure 2. Frequency of keywords. (Source: Authors)

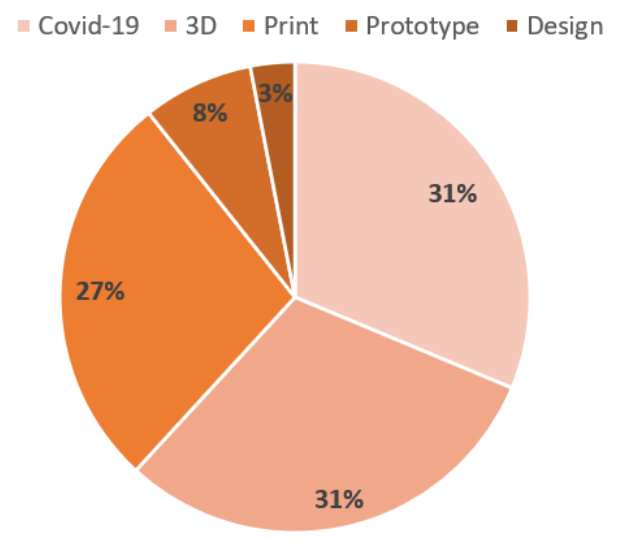


The research identified publications as articles and a diversity of content of a scientific nature, being analyzed according to their possible contributions to the theme, among them a design realized in Simplify3D containing a guide for the modeling and assembly description of the faceshield product. The intent of the guide was to contribute with instructions for that could be used by other researchers and designers in the development of the equipment, and subsequently distributed for health teams. In analysis, it was checked that $68 \%$ of the publications found were scientific articles, $24 \%$ of publications of a diverse character and $8 \%$ were summarized in technical notes and technical reports. Almost $1 / 4$ of the sample's publications disseminated the knowledge acquired in the pandemic in other ways besides the usual articles. The results can be seen in figure 3 .

Figure 3. Distribution by type of publication. (Source: Authors)

$\square$ Article $\quad$ Others $\square$ Technical note $\square$ Technical reports

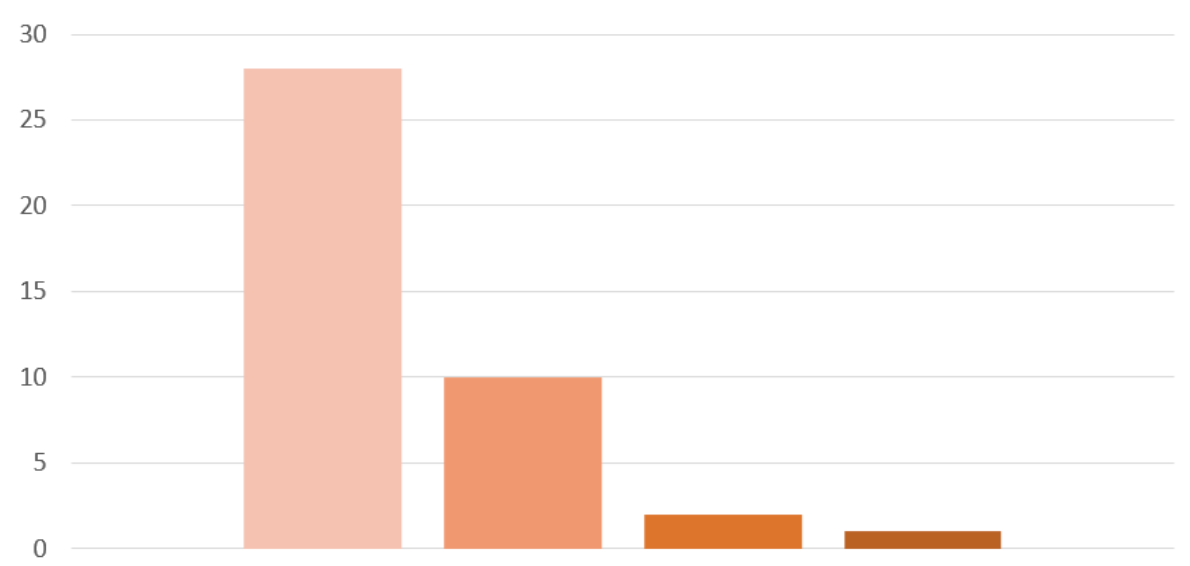

As for the frequency of publications, a cutout was realized from March to July 2020. The graph in figure 4 shows the month of March was the lowest publication launch rate within the theme addressed, which is ratified with data released daily by WHO [4]. The data indicate that the number of confirmed cases of the coronavirus reached around five hundred thousand people by March 30, 2020. The growing number of cases resulted in a rapid mobilization in the development of PPE due to the limited supply of products around the world. The period of greatest attendance in published works was in June. Amid the rapid responses to the health system, there were around 13 publications on the theme analyzed. Between April and July 2020, there was an average of 10 publications per month, demonstrating a great commitment in the theme. The data identified by month can be seen in figure 4 .

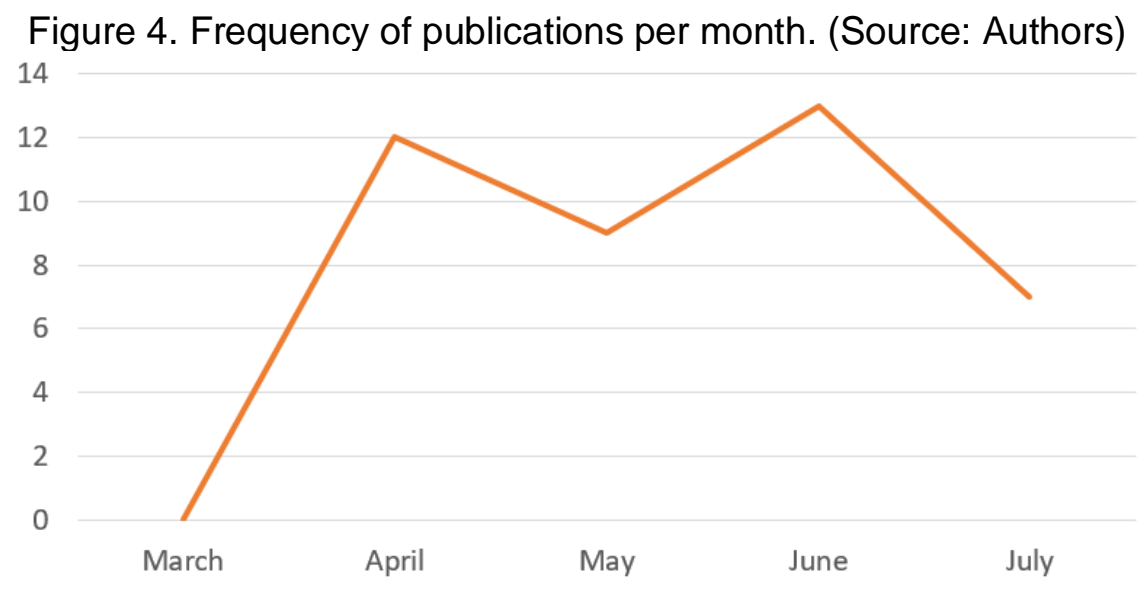


As for the databases, there are peculiarities. Despite the CAPES Periodical covering a large collection of scientific journals, it was difficult to find publications within the selected criterion, regarding the areas of design and engineering, which were the only ones evaluated. Similarly, it occurred with the Scielo source, on the verge of only one publication was within the considered criteria.

In Science Direct, according to the website's own search engine, 42 publications were found when the keywords were marked. However, approximately $17 \%$ includes the established criterion. The Medline database was considered relevant due to the publications categorized in the area of medicine, being the database with the largest number of publications based on the evaluated criteria and reinforcing the use of design and engineering applied to medicine. As for Research Gate, a range of around 100 results was found. However, it was noted that a considerable part of these were repetitions of publications already found in the previous databases. But, it was possible to consider publications that were not repeated and that fit the criteria of this article, so that it promoted a greater diversification of results. The results are seen in figure 5 .

Figure 5. Distribution of publications by source in the period studied. (Source: Authors)

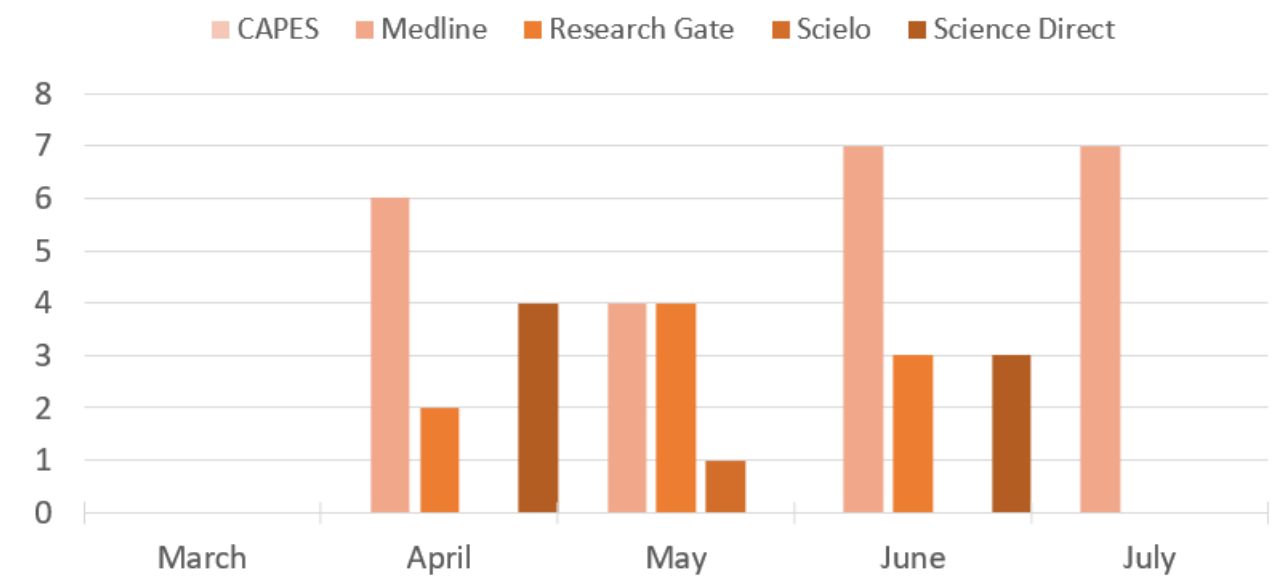

During the evaluation of the sample, it was identified the publications describe the development and implementation of 3D printed devices in the fight against the pandemic. In the analysis of publications, regarding the types of PPE studied, a greater frequency is noted in the report on facial masks and facial protectors. In some cases, the mask type is specified, the most common being the N95 mask. Despite being less cited, works related to facial respirators were also found. Other medical devices or equipment cited were nasopharyngeal SWAB used for clinical tests, and ventilators.

In short, regarding the information on the analyzed topic, it stands out as relevant, according to its thematic proximity and research format, as follows:

Some publications carried out research in a literature review format. There have been studies and analyzes that have mapped the challenges faced by the health system during the pandemic period, the main one being the distribution of PPE to health professionals. In addition, they focused on the management of emerging technologies such as 3D printing (because it is cheap, innovative and easy to customize) to supply the lacking medical products. To mitigate the scarcity of the mentioned equipment, most studies emphasize 3D printing as support for: a) nasopharyngeal SWAB in tests of the disease; b) facial scanning and manufacture of 
N95 masks, aiming at the user's comfort; c) analysis of PPE models (e.g. faceshield) from CAD files made available in open code, also the recommendations and guide for amateur people to print in the current scenario; d) discuss the use of rapid prototyping, considering the support of suppliers and designers; e) manufacture of medicines for oral use during the pandemic; f) solve challenges of future outbreak events.

Other works developed different and fast 3D printing solutions to meet the needs of the period, which are: a) door opening devices, door hooks and push button, without the use of hands; b) manufacture and implementation of nasopharyngeal SWAB; c) development of pulsoximeter components; d) adaptation of the faceshield for use of headlight by otolaryngologist; e) conversion of: arthroplasty helmet (Flyte) and diving mask (Easybreath) to replace masks in clinical practices; f) development of printed splints to decrease the contact time between patient and doctor during the implantation of plaster; g) integration of respirators, breathing filters and printed adapter; $h$ ) low cost simulation for medical trainees to practice the insertion of pedicle screws in the lumbar spine without physical contact during the pandemic; i) development of faceshield that have air filters and forced ventilation, being recharged via USB.

The works that adopted $3 \mathrm{D}$ printing in a simplistic way resulted in: a) development of methods, fast alternatives and manufacture of faceshields with low cost and good precision, both for the support and the visor; b) manufacturing and digital customization of masks using a 3D scanner via smartphone and free CAD software; c) manufacture of a spare frame for replacement in N95 masks, seeking to extend the life of the PPE; d) production of specific faceshields for interventionist radiologists.

Finally, more similar works described the easy dissemination of PPE projects (faceshields) shared in open source and to be carried out in 3D printing, bringing: a) vision of the community in general regarding the sharing of files ready for printing; $b$ ) masks with reusable filters shared in open code; c) research for 3D printed PPE regulations, aiming to guarantee the N95 standards and minimize the occupational risks of health professionals.

According to Corsini et al [5], there is a range of digital manufacturing techniques available that can help satisfy the urgency of medical supplies, sanitation, utilities and spare parts. This corroborates as seen in the publications. The productions considered demonstrate that we already have the knowledge and technology necessary to use 3D printing as a way to accelerate the insertion of new products on the market. It is evident the motivation brought by the pandemic, in this case the search to save lives, intensified the reaction of the scientific community and the industry to promote a fast and assertive way to combat the dissemination of the coronavirus.

According to the data presented, the circumstances of this global crisis brought the theme to the center of the focus, once in March 2020 there were still no publications focused on the use of 3D printing to combat the covid-19. However, since April, the theme became relevant, especially in the medical area as evidenced by publications from the Medline source, within the established criteria. 


\section{CONCLUSION}

The article aimed to highlight the importance of rapid prototyping as a resource in the development of products in the short time, through the contributions of research that address the theme applied to the covid-19 moment. Quantitative research was used as a method to analyze the works published in the period from March to July 2020 , which finally showed the growing strength the theme has been receiving.

Of the studies analyzed, $88 \%$ explained the use of 3D printing to solve specific problems caused by the coronavirus, such as the scarcity of facial masks in health units. It was verified, through the summaries of the publications analyzed in the sample, the contribution of rapid prototyping in the development of medium complexity solutions against covid-19, being highlights: devices to minimize physical contact between patients and health professionals; the large scale of manufacturing faceshields and masks, adapting other artifacts to become PPE and SWAB devices for clinical testing.

\section{REFERENCES}

${ }^{1}$ SINGH, S., PRAKASH, C., RAMAKRISHNA, S. Three-dimensional printing in the fight against novel virus COVID-19: Technology helping society during an infectious disease pandemic. Technology in Society, v. 62, 2020. Available at: https://www.sciencedirect.com/science/article/pii/S0160791X20303936. Accessed on: 12 jul. 2020.

${ }^{2}$ BAIÃO, F. J. Funcionalidades e tecnologias da impressora 3D. 2012. $46 \mathrm{f}$. Trabalho de Conclusão de Curso (Graduação em Engenharia da Computação) Universidade São Francisco, Itatiba, 2012. Available at: https://docplayer.com.br/7981827-Funcionalidades-e-tecnologias-da-impressora3d.html. Accessed on: 27 jul. 2020.

${ }^{3}$ GERHARDT, Tatiana Engel; SILVEIRA, Denise Tolfo (organizadoras). Métodos de Pesquisa. $1^{\underline{a}}$ Ed. Porto Alegre: Editora da UFRGS, 2009.

${ }^{4}$ WORLD HEALTH ORGANIZATION (WHO). Geneva, 2020. Available at: <https://covid19. who.int/>. Accessed on: 1 ago 2020.

${ }^{5}$ CORSINI, L, ARANDA-JAN, C.B., MOULTRIE, J. Using digital fabrication tools to provide humanitarian and development aid in low-resource settings. Technology in Society, $\quad$ v. $58, \quad 2019 . \quad$ Available at: https://www.sciencedirect.com/science/article/pii/S0160791X18302264. Accessed on: 18 jul. 2020. 